\title{
Withdrawal syndrome after donepezil cessation in a patient with dementia
}

\author{
Leszek Bidzan • Mariola Bidzan
}

Received: 15 February 2011/Accepted: 5 January 2012/Published online: 15 January 2012

(C) The Author(s) 2012. This article is published with open access at Springerlink.com

\begin{abstract}
We describe a 62-year-old female diagnosed with Alzheimer's disease, who had been treated with donepezil for approximately 1 year. When she developed a low-grade fever and digestive complaints, her family physician interpreted these symptoms as side effects of the drug and ordered donepezil to be discontinued. Not only was there no improvement of the somatic symptoms after discontinuation of donepezil, but there was also a worsening of the dementia symptoms, culminating in delirium. When donepezil was re-prescribed, the delirium resolved and the patient's mental state stabilized. The authors urge great caution in discontinuing treatment with acetylcholinesterase inhibitors such as donepezil.
\end{abstract}

Keywords Acetylcholinesterase inhibitors ·

Alzheimer's disease · Anticholinergic agents · Delirium

\section{Introduction}

Donepezil is a selective inhibitor of acetylcholinesterase, used in the treatment of Alzheimer's disease (AD). The administration of acetylcholinesterase inhibitors (IAchEs) should be systematic and long term. However, for numerous reasons IAchEs are often abruptly terminated. The causes of this most often include the occurrence of side

L. Bidzan $(\bowtie)$

Department of Developmental, Psychotic, and Geriatric Psychiatry, Medical University of Gdansk, Srebrniki 1, 80-282 Gdańsk, Poland

e-mail: leszekbidzan@gumed.edu.pl

M. Bidzan

Institute of Psychology, Gdansk University, Gdańsk, Poland

e-mail: mariola.bidzan@gmail.com effects, lack of efficacy, or sometimes caregiver error or negligence [1]. Terminating treatment, especially abruptly, is not without consequences for the patient. It has been reported that intense hallucinations can occur after sudden donepezil withdrawal [2]. One published study has suggested that discontinuation of treatment with donepezil may bring withdrawal symptoms [3]. Attempts have also been made to use donepezil to reduce delirium in patients with dementia [4-6]. There has also been a reported case of a patient who became delirious 3 days after he had begun to take donepezil [7].

Below we present a clinical case from our own practice, describing a patient who had been treated with donepezil for several months, while the sudden termination of the drug caused delirium.

\section{Case report}

This 62-year-old woman was first seen by a psychiatrist in 2007. About 10 months before this consultation, the family physician had diagnosed her with mild dementia. An MRI examination revealed generalized cortical degeneration, especially in the medial temporal lobes. The patient's MMSE score was 21 points, and her ADAS-cog score was 22 points. Standard laboratory tests revealed no clinically significant abnormalities. Alzheimer's disease was diagnosed, and donepezil (in generic form) was prescribed, at a dosage of $5 \mathrm{mg}$ daily. As the drug was tolerated so well by the patient, after 6 weeks the dosage was increased to $10 \mathrm{mg}$ once a day.

The patient took donepezil systematically until August 2008. During that period she was taking no other drugs, except for a few cold remedies (paracetamol, aspirin). She reported for regular checkups with her caregiver (her husband) once every 4 weeks on average. Her mental state 
was found to be stable. No significant abnormalities were found in laboratory tests or EKG examination.

In August 2008, the patient had symptoms of a somatic disease. Due to difficult communication with the patient, the only complaints that could be confirmed were headaches and stomachaches. She had no appetite. Her temperature went up to $37.8^{\circ} \mathrm{C}$, and the heart rate was 90 . There were slight electrolyte changes: $104 \mathrm{mmol} / \mathrm{l} \mathrm{Cl}$, $4.0 \mathrm{mmol} / \mathrm{l} \mathrm{K}, 147 \mathrm{mmol} / \mathrm{l} \mathrm{Na}$. There were no clinically significant changes in urine culture and hematology, apart from mild increase in some parameters of white cell count (total WBC and neutrophils). Based on the digestive symptoms (aches, loss of appetite), the family physician decided that the symptoms were probably a side effect of donepezil treatment and recommended termination of treatment. For the next $24 \mathrm{~h}$, the patient did not improve: she remained bedridden, and her temperature was still $37.7^{\circ} \mathrm{C}$.

Within 3 days after the medicine had been withdrawn, the caregiver asked for psychiatric consultation due to significantly intensified dementia symptoms and increased anxiety. During the consultation, the patient showed a fluctuating level of consciousness and was unable to pay full attention; her behavior also demonstrated possible hallucinations. An attempt to conduct a neuropsychological assessment failed because of her fluctuating level of consciousness. The patient had also not slept the previous two nights, which increased her anxiety. Delirium was diagnosed, together with a somatic infection, on the basis of prior morphological tests and the clinical state. It was decided that donepezil should be reintroduced in the previous dosage of $10 \mathrm{mg}$, but divided into $2 \times 5 \mathrm{mg}$. Antiinflammatory treatment was also prescribed: aspirin $(1,500 \mathrm{mg})$ and ascorbic acid. EKG and X-ray examinations were also recommended.

Two days later, the patient was consulted again at home. Her behavior was calm, it was possible to cooperate with her, and there were no signs that would indicate the presence of psychotic symptoms. She still showed a loss of appetite and stayed in bed most of the time. The EKG and $\mathrm{X}$-ray examinations had not revealed any pathological changes. Her temperature was $36.8^{\circ} \mathrm{C}$, and her pulse was 82. According to the patient's husband, she had calmed down significantly the next day after taking donepezil and had slept from early morning.

Five days after renewing donepezil treatment, her husband called to inform that the patient had regained her appetite and was no longer bedridden; her temperature was normal. A subsequent consultation in the outpatient clinic took place 7 days later (14 days after the delirium). The patient did not display a fluctuating level of consciousness; she was disoriented in time, but not in space, and was able to concentrate. However, once in every few hours, she demonstrated increased agitation and intensified disorientation. These episodes lasted from several minutes to about an hour. According to her husband, the patient wanted to leave home at these times and displayed great anxiety. Verbal persuasion was sufficient to keep her at home and calm her down after some time. Her MMSE score was now 17, and the ADAS-cog score was 34. No significant abnormalities were found in laboratory tests. The former dosage of donepezil was reintroduced (10 $\mathrm{mg}$ in one dose).

During subsequent monthly consultations, no disorders of consciousness were observed. Short-lasting episodes of agitation and intensified disorientation lasted for 10 days after reintroducing donepezil and then receded.

A complete follow-up examination, including neuropsychological assessment, was done within 6 months after the delirium episode. This examination confirmed intensification of cognitive deficiency, which was revealed a week after the delirium, but without any features of further progression in the following months.

\section{Discussion}

Delirium is very common in many geriatric diseases. It is often not diagnosed, and is frequently connected with unfavorable prognosis [8]. The occurrence of delirium is dependent on a number of factors. Dementive disorders make the occurrence of delirium more probable [9]. Delirium seems to have an influence on the further progression of dementia [10].

Greater importance is ascribed to acetylcholine than to the other cerebral neurotransmitters in the pathogenesis of delirium. It has been proved that there is a connection between delirium and numerous substances that influence the level of acetylcholine in the reticular formation [11]. A relation has also been noticed between the intensity of delirium symptoms and the concentration of anticholinergic substances [12].

In the described case, there is a visible temporal connection between withdrawing donepezil and the occurrence of delirium. However, several factors occurred at one time, including an infection, which caused an increase in temperature and immobilization. The loss of appetite prompted an increased intake of fluids, which was indicated by discrete electrolytic abnormalities. All these factors are considered to be risk factors for delirium [13]. Nevertheless, the rapid improvement of our patient's mental state after administering donepezil again, despite lingering somatic symptoms, proves its key role in the etiology of delirium in this case. The improvement occurred within just a few hours after the medicine had been taken, which may be connected with the fact that peak plasma levels of donepezil are reached in 3-4 h. On the other hand, the 
transient states of agitation and intensified disorientation that appeared within several days after the delirium, could be connected with steady-state concentration, which is achieved within 15-21 days [14]. Clinical symptoms in our patient manifested markedly earlier than in cases described by Singh and Dudley [3]. This difference probably results from the influence of additional factors in our patient, namely infection and the fact that she was not administered other psychotropic agents [3].

This case illustrates the necessity of maintaining extreme caution when making the decision to terminate treatment with chronically administrated drugs in dementia, particularly in the presence of other potential risk factors for delirium.

Open Access This article is distributed under the terms of the Creative Commons Attribution Noncommercial License which permits any noncommercial use, distribution, and reproduction in any medium, provided the original author(s) and source are credited.

\section{References}

1. Umegaki H, Itoh A, Suzuki Y, Nabeshima T (2008) Discontinuation of donepezil for the treatment of Alzheimer's disease in geriatric practice. Int Psychogeriatr 20:800-806

2. Minett TS, Thomas A, Wilkinson LM, Daniel SL, Sanders J, Richardson J, Littlewood E, Myint P, Newby J, McKeith IG (2003) What happens when donepezil is suddenly withdrawn?
An open label trial in dementia with Lewy bodies and Parkinson's disease with dementia. Int J Geriatr Psychiatry 18:988-993

3. Singh S, Dudley C (2003) Discontinuation syndrome following donepezil cessation. Int J Geriatr Psychiatry 18:282-284

4. Wengel SP, Roccaforte WH, Burke WJ (1998) Donepezil improves symptoms of delirium in dementia: implications for future research. J Geriatr Psychiatry Neurol 11:159-161

5. Wengel SP, Burke WJ, Roccaforte WH (1999) Donepezil for postoperative delirium associated with Alzheimer's disease. J Am Geriatr Soc 47:379-380

6. Burke WJ, Roccaforte WH, Wengel SP (1999) Treating visual hallucinations with donepezil. Am J Psychiatry 156:1117-1118

7. Kawashima T, Yamada S (2002) Delirium caused by donepezil: a case study. J Clin Psychiatry 63:250-251

8. Johnson JC, Kerse NM, Gottlieb G, Wanich C, Sullivan E, Chen K (1992) Prospective versus retrospective methods of identifying patients with delirium. J Am Geriatr Soc 40:316-319

9. Levkoff S, Cleary P (1991) Epidemiology of delirium: an overview of research issues and findings. Int Psychogeriatr 3:149-167

10. McCusker J, Cole M, Dendukuri N, Belzile E, Primeau F (2001) Delirium in older medical inpatients and subsequent cognitive and functional status: a prospective study. CMAJ 165:575-583

11. Lipowski ZJ (1990) Intoxication with medical drugs. In: Delirium: acute confusional states. Oxford University Press, New York

12. Flacker JM, Cummings V, Mach JR Jr, Bettin K, Kiely DK, Wei J (1998) The association of serum anticholinergic activity with delirium in elderly medical patients. Am J Geriatr Psychiatry 6:31-41

13. American Psychiatric Association (1999) Practice guideline for the treatment of patients with delirium. Am J Psychiatry 156(5 Suppl): $1-20$

14. Seltzer B (2005) Donepezil: a review. Expert Opin Drug Metab Toxicol 1:527-536 